\title{
Effects of Pollution on Fish Behavior, Personality, and Cognition: Some Research Perspectives
}

\author{
Lisa Jacquin ${ }^{1,2 *}$, Quentin Petitjean ${ }^{1,3}$, Jessica Côte ${ }^{1}$, Pascal Laffaille $^{3}$ and \\ Séverine Jean ${ }^{2,3}$ \\ 1 Laboratoire EDB Évolution \& Diversité Biologique UMR 5174, Université de Toulouse, UPS, CNRS, IRD, Toulouse, France, \\ ${ }^{2}$ LTSER France, Zone Atelier PYGAR «Pyrénées-Garonne ", Auzeville-Tolosane, France, ${ }^{3}$ Laboratoire EcoLab UMR 5245, \\ Université de Toulouse, UPS, CNRS, INPT-ENSAT, Castanet-Tolosan, France
}

\section{OPEN ACCESS}

Edited by:

Elise Huchard,

UMR5554 Institut des Sciences de l'Evolution de Montpellier (ISEM),

France

Reviewed by:

Andrea Grunst,

University of Antwerp, Belgium

Laure Cauchard,

University of Aberdeen,

United Kingdom

*Correspondence:

Lisa Jacquin

lisa.jacquin@univ-t/se3.fr

Specialty section:

This article was submitted to Behavioral and Evolutionary Ecology, a section of the journal

Frontiers in Ecology and Evolution

Received: 18 October 2019

Accepted: 16 March 2020

Published: 07 April 2020

Citation:

Jacquin L, Petitjean Q, Côte J, Laffaille $P$ and Jean S (2020) Effects

of Pollution on Fish Behavior. Personality, and Cognition: Some

Research Perspectives.

Front. Ecol. Evol. 8:86.

doi: 10.3389/fevo.2020.00086
Pollutants, and more generally, environmental stressors, are a neglected source of behavioral and cognitive variations in wild populations. Based on recent literature in fish, we highlight four interesting research perspectives to better understand the effects of pollutants on the links between fish behavior, cognition and fitness. First, (1) we review the neurotoxic effects of pollutants on fish behavior, personality, and cognition. These behavioral and cognitive effects could in turn affect the level of exposure to pollutants, potentially generating feedback loops that may amplify the effects of pollutants on fish fitness. Second, we propose that (2) the effects of pollutants should be studied in a multistress context, i.e., in realistic environmental conditions in combination with other stressors, because some stressors could amplify the behavioral effects of pollutants on fitness. Third (3), existing studies show that physiology, personality, cognition, and fitness components are often linked in syndromes. Pollutants could lead to syndrome disruption, which could affect the evolutionary trajectories of exposed populations. Future studies should thus focus on the complex links between traits to better understand the consequences of stressors on evolutionary trajectories. Fourth, (4) exposure to chronic pollution could lead to local adaptation or maladaptation, which could result into high intraspecific variability of sensitivity among wild populations. In addition, evolutionary responses to pollution could constrain, or be constrained by evolutionary responses to other stressors. We thus encourage future studies to use integrative approaches to bridge the gap between ecotoxicology, cognitive ecology and evolutionary ecology in a multistress framework to tackle these exciting questions and improve our ability to predict the effects of anthropogenic stressors on wildlife.

Keywords: temperament, contamination, global change, stress response, multistress, evolutionary ecotoxicology, local adaptation

\section{INTRODUCTION}

Human activities are the sources of many organic and inorganic contaminants such as plastics, pharmaceuticals, pesticides, and metals that have alarming impacts on terrestrial and aquatic ecosystems (Scott and Sloman, 2004; Zala and Penn, 2004; Saaristo et al., 2018). However, our ability to accurately predict their effects on wildlife is limited by several scientific challenges. Direct effects of pollutants on animal physiology and mortality have been included as part of routine ecotoxicology studies (Butcher et al., 2006; Ashauer et al., 2013), but more complex behavioral 
effects on animal personality and cognition are less studied, especially in wild species and in realistic multistress conditions (Zala and Penn, 2004; Saaristo et al., 2018). In addition, the links between behavioral changes, cognitive performances, and individual fitness are rarely taken into account when studying contaminant effects, which limits our ability to predict the cascading long-term impacts of human activities on population persistence and evolutionary trajectories.

Here, we review the existing literature focusing on fish to investigate the behavioral effects of pollutants in a multistress perspective. Fish have been widely used for behavioral and cognitive assays (Brown et al., 2006), and are used as "sentinel" animals in ecotoxicology (Giulio and Hinton, 2008; Braunbeck et al., 2013). We thus summarized (non-extensively) the existing literature on the behavioral effects of pollutants in wild fish (Table 1). As shown in Table 1, most previous studies used ecologically relevant pollution levels, but they tested the effects of contamination alone, i.e., in a single stressor framework. However, pollution effects are often modulated by a concomitant exposure to other natural or human-induced stressors in the wild (Schinegger et al., 2016), which could result into synergistic interactions and/or amplified effects on fish fitness (e.g., Gandar et al., 2015, 2017a). Nonetheless, empirical data on multistress effects on fish behavior are still rare (Table 1). In addition, strong correlations often exist between traits (Réale et al., 2007; Conrad et al., 2011; Sih, 2011; Sih and Del Giudice, 2012), but most studies have measured behavioral traits in isolation (Table 1), and pollutant effects on syndrome structure are still unclear (Killen et al., 2013; Montiglio and Royauté, 2014). Finally, most previous studies used domestic species or a single population of wild species, so that the interpopulation variability and the evolution of behavioral responses to pollution are rarely taken into account (Table 1). Exploring the effects of pollutants on fish fitness through behavioral and cognitive alterations in wild populations and their evolutionary implications is thus an exciting scientific challenge for the next decades.

Based on the existing knowledge gaps, we highlight four promising research perspectives to better understand the effects of pollution on behavior, cognition and their consequences for fish fitness and population persistence (Figure 1). First, we propose that (1) pollution may alter several behavioral traits, as well as learning and memory abilities, with potential cascading effects on fish fitness. Pollution-induced behavioral alterations could potentially further increase the level of exposure to pollution in the wild, resulting in positive feedback loops that could potentially amplify pollution effects on fitness. Second, we propose that (2) exposure to multiple stressors might now be the rule, so that pollutants should be studied in combination with other stressors that often modify the effects of pollutants on fish behavior and fitness. Third, (3) stressors such as pollutants could affect the links between physiology and behavior, leading to syndrome disruption or reinforcement, with important consequences for evolutionary trajectories. Fourth, we discuss how (4) chronic pollution could lead to local adaptation or maladaptation, due to plastic and/or genetic changes caused by pollutants. Behavioral and cognitive responses are central in adaptive processes, because they are shaped by past evolution, and can in turn facilitate or impede adaptive responses to pollution and other stressors (Sih et al., 2011) (Figure 1). With this study, we hope to encourage future studies to use integrative approaches bridging the gap between behavioral, cognitive and evolutionary ecology to tackle these challenging questions and to better understand the impacts of current and future stressors on wild fish populations.

\section{EFFECTS OF POLLUTANTS ON FISH BEHAVIOR AND FEEDBACK LOOPS}

Many pollutants have direct and indirect effects on the behavior of terrestrial and aquatic organisms (Clotfelter et al., 2004; Zala and Penn, 2004; Saaristo et al., 2018), especially in fish (Scott and Sloman, 2004; Robinson, 2009; Sloman and McNeil, 2012). Inorganic and organic pollutants affect a wide array of behaviors such activity, exploration, avoidance, sociability, aggressiveness, sexual and feeding behaviors (summarized in Table 1). Some studies have also tested the effects of contaminants on behavioral types, or personalities, i.e., on consistent interindividual variations in behavior (Réale et al., 2007, 2010; Montiglio and Royauté, 2014). In addition, many contaminants affect fish cognitive performances (Table 1), with potential cascading effects on fitness (e.g., de Castro et al., 2009).

Some of these changes are underpinned by alterations of cholinesterase activity, neurotransmitter or hormone levels (Scott and Sloman, 2004; Brodin et al., 2014; Vindas et al., 2017). For instance, carbofuran pesticide alters neurofunction and activity in sea bass Dicentrarchus labrax (Hernández-Moreno et al., 2011). Fluoxetine antidepressant (Prozac) alters aggression, boldness and learning in the Siamese fighting fish Betta splendens by altering the serotonin system (Kohlert et al., 2012; Eisenreich and Szalda-Petree, 2015; Dzieweczynski et al., 2016). Other behavioral changes could be indirectly due to changes in energetic balance (Montiglio and Royauté, 2014), due to the costs of detoxification and stress responses (Sokolova et al., 2012; Sokolova, 2013). For instance, low doses of pesticides decreased activity in goldfish Carassius auratus, likely due to increased costs of detoxication and physiological defenses (Gandar et al., 2015, 2017a,b). However, more work is needed to fully understand the neuronal and physiological underpinnings of pollution-driven alterations of behavior and cognition (Brodin et al., 2014).

Interestingly, pollution-induced changes in behaviors could potentially increase further the level of exposure to pollution and result into positive feedback loops amplifying the negative effects of pollution on fish fitness. However, only indirect evidence exists so far. Indeed, spatial behaviors such as activity, exploration, and avoidance are key behavioral traits that are often affected by pollution. For instance, individuals living in metal polluted sites (lead and cadmium) and having higher levels of metal in their blood displayed slower exploration tendencies in great tits Parus major (Grunst et al., 2018, 2019). In another example, Trinidadian guppies Poecilia reticulata exposed to crude-oil had decreased exploration tendency in an experimental maze (Jacquin et al., 2017). Such impaired exploration tendencies could in turn affect fish ability to assess habitat quality, 
TABLE 1 | Non-extensive summary of the existing literature on the link between pollution and behavior in fish.

\begin{tabular}{|c|c|c|c|c|c|c|c|}
\hline Contaminant & $\begin{array}{l}\text { Ecological } \\
\text { relevance }\end{array}$ & Fish species & Behavioral traits & Multi-stress & Syndrome & Variability & Source \\
\hline \multicolumn{8}{|l|}{ Plastics } \\
\hline Microplastics & Yes & $\begin{array}{l}\text { Acanthochromis } \\
\text { polyacanthus }\end{array}$ & $\begin{array}{l}\text { Activity, feeding, } \\
\text { aggression }\end{array}$ & No & No & Yes & $\begin{array}{l}\text { Critchell and } \\
\text { Hoogenboom (2018) }\end{array}$ \\
\hline Nanoplastics & Yes & Carassius carassius & $\begin{array}{l}\text { Activity, feeding, } \\
\text { exploration }\end{array}$ & No & No & No & Mattsson et al. (2017) \\
\hline Oxazepam & Yes & Perca fluviatilis & $\begin{array}{l}\text { Activity, boldness, } \\
\text { sociality, feeding rate }\end{array}$ & No & Yes & No & Brodin et al. (2013) \\
\hline $\begin{array}{l}\text { Vinclozolin, flutamide } \\
\text { (chemotherapy) }\end{array}$ & Yes & Betta splendens & $\begin{array}{l}\text { Activity, shoaling, } \\
\text { exploration, boldness }\end{array}$ & No & Yes & No & $\begin{array}{l}\text { Dzieweczynski et al. } \\
\text { (2018) }\end{array}$ \\
\hline Ethinylestradiol & Yes & Betta splendens & Boldness, activity & No & Yes & No & $\begin{array}{l}\text { Dzieweczynski et al. } \\
\text { (2014) }\end{array}$ \\
\hline $\begin{array}{l}\text { Various psychiatric } \\
\text { drugs }\end{array}$ & Yes & Several species & $\begin{array}{l}\text { Boldness, aggression, } \\
\text { activity, feeding, anxiety }\end{array}$ & No & No & No & Brodin et al. (2014) \\
\hline Oxazepam & Yes & Salmo salar & Migration & Yes & No & No & $\begin{array}{l}\text { Hellström et al. (2016); } \\
\text { Klaminder et al. (2019) }\end{array}$ \\
\hline Mixture & Yes & $\begin{array}{l}\text { Neogobius } \\
\text { melanostomus }\end{array}$ & Aggression & No & No & Yes & McCallum et al. (2017) \\
\hline Chlorpyryfos & & Danio rerio & Spatial learning & No & No & No & Levin et al. (2003) \\
\hline Glyphosate & Yes & $\begin{array}{l}\text { Piaractus } \\
\text { mesopotamicus }\end{array}$ & Feeding & No & No & No & Giaquinto et al. (2017) \\
\hline Glyphosate & Yes & Danio rerio & $\begin{array}{l}\text { Exploration, } \\
\text { locomotion, } \\
\text { aggression, memory }\end{array}$ & No & No & No & Bridi et al. (2017) \\
\hline $\begin{array}{l}\text { Atrazine, linuron, } \\
\text { metolachlor }\end{array}$ & Yes & Oncorhynchus mykiss & Aggression, locomotion & No & No & No & Shinn et al. (2015) \\
\hline Ethoprofos & Yes & Astyanax aeneus & $\begin{array}{l}\text { Avoidance, escape } \\
\text { behavior }\end{array}$ & Yes & No & No & $\begin{array}{l}\text { Sandoval-Herrera et al. } \\
\text { (2019) }\end{array}$ \\
\hline Carbofuran & Yes & Dicentrarchus labrax & Swimming activity & No & No & No & $\begin{array}{l}\text { Hernández-Moreno } \\
\text { et al. (2011) }\end{array}$ \\
\hline $\begin{array}{l}\text { Carbaryl, diazinon, } \\
\text { malathion }\end{array}$ & Yes & Oncorhynchus mykiss & Swimming activity & No & Yes & No & Beauvais et al. (2001) \\
\hline \multicolumn{8}{|l|}{ Other Organic Pollutants } \\
\hline PCB, PeBDE & Yes & Fundulus heteroclitus & Activity, feeding & No & No & No & $\begin{array}{l}\text { Timme-Laragy et al. } \\
\text { (2006); Couillard et al. } \\
\text { (2011) }\end{array}$ \\
\hline
\end{tabular}


TABLE 1 | Continued

\begin{tabular}{|c|c|c|c|c|c|c|c|}
\hline Contaminant & $\begin{array}{l}\text { Ecological } \\
\text { relevance }\end{array}$ & Fish species & Behavioral traits & Multi-stress & Syndrome & Variability & Source \\
\hline $\begin{array}{l}\text { Nonylphenol (industrial } \\
\text { surfactant) }\end{array}$ & Yes & Fundulus diaphanus & Shoaling, recognition & No & No & No & Ward et al. (2008) \\
\hline \multicolumn{8}{|l|}{ Metals } \\
\hline Mercury & & Danio rerio & Activity, escape & Yes & No & No & Weber (2006) \\
\hline Methylmercury MeHg & & Danio rerio & Anxiety, locomotion & No & No & No & Maximino et al. (2011) \\
\hline $\mathrm{MeHg}$ & Yes & Fundulus heteroclitus & Activity, feeding & No & No & Yes & $\begin{array}{l}\text { Zhou and Weis }(1998) ; \\
\text { Weis et al. }(1999,2001)\end{array}$ \\
\hline Metal mixture & Yes & Pimephales promelas & Swimming performance & No & No & No & Kolok et al. (1998) \\
\hline $\mathrm{MeHg}$ & Yes & Fundulus heteroclitus & Sociality & No & No & Yes & $\begin{array}{l}\text { Ososkov and Weis } \\
\text { (1996) }\end{array}$ \\
\hline $\mathrm{MeHg}$ & No & Danio rerio & Spatial learning & No & No & No & Smith et al. (2010) \\
\hline $\begin{array}{l}\text { Several metals (Cu, } \\
\mathrm{Zn}, \ldots)\end{array}$ & No & Several species & Avoidance, activity & No & No & No & Atchison et al. (1987) \\
\hline $\mathrm{Ag}$ & Yes & Danio rerio & $\begin{array}{l}\text { Avoidance, swimming, } \\
\text { spatial learning }\end{array}$ & No & No & No & Powers et al. (2011) \\
\hline $\mathrm{Cd}$ & Yes & Oncorhynchus mykiss & Sociality & No & No & No & Sloman et al. (2003) \\
\hline PCBs and PAHs & Yes & Ameiurus nebulosus & $\begin{array}{l}\text { Aggression, activity, } \\
\text { escape response }\end{array}$ & No & No & Yes & $\begin{array}{l}\text { Breckels and Neff } \\
\text { (2010) }\end{array}$ \\
\hline $\begin{array}{l}\text { Trenbolone (agricultural } \\
\text { pollution) }\end{array}$ & Yes & Poecilia reticulata & Reproductive behaviors & No & No & No & $\begin{array}{l}\text { Bertram et al. (2015); } \\
\text { Tomkins et al. (2018) }\end{array}$ \\
\hline $\begin{array}{l}\text { PAHs Polycyclic } \\
\text { aromatic hydrocarbons }\end{array}$ & NA & Poecilia reticulata & $\begin{array}{l}\text { Exploration, activity, } \\
\text { sociality }\end{array}$ & No & No & Yes & Jacquin et al. (2017) \\
\hline Benzo[a]pyrene & NA & Oncorhynchus kisutch & Territoriality & No & No & No & Ostrander et al. (1988) \\
\hline PAHs & Yes & $\begin{array}{l}\text { Neogobius } \\
\text { melanostomus }\end{array}$ & Competition & No & No & Yes & Sopinka et al. (2010) \\
\hline
\end{tabular}

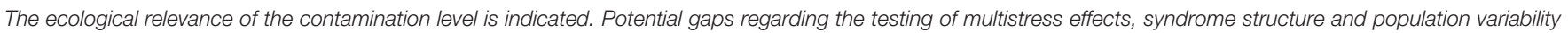
are also reported.

because exploration is a key trait enabling individual to gather information and cues about their environment (Reader, 2015). Social interactions are also often altered by contamination (e.g., Ward et al., 2008), which could decrease social learning and the acquisition of information from conspecifics (Laland and Williams, 1997; Brown and Laland, 2003).

Spatial cognitive abilities such as spatial memory and spatial learning ability are also often deeply impacted by contaminants. For instance, aluminum contamination impaired learning performance in a maze task in Atlantic salmon Salmo salar, which could decrease their ability to process information and cope with new environments (Grassie et al., 2013). Organic pollutants such as pesticides also disturbed activity and spatial memory in zebrafish Danio rerio and rare minnow Gobiocypris rarus (Hong and Zha, 2019). Such adverse cognitive effects are expected to have severe consequences for fish ability to learn and memorize information to escape predators, find food and mates, and to avoid polluted areas and food items. Contaminated fish could thus have difficulties to collect, process and memorize information about habitat and food quality, which might further affect their exposure to pollution and result into positive feedback loops. In addition, many pollutants affect dispersal and migration, which could affect the exposure of animals to pollution. For instance, pesticides and pharmaceuticals alter downward migration and homing behaviors in salmonid fish (e.g., Scholz et al., 2000; Hellström et al., 2016; McCallum et al.,
2019), which could potentially expose them to higher levels of pollution if they cannot return to their clean home river. However, furher work is needed to test these hypotheses.

Pollution also affects fish boldness, appetite, foraging patterns, which could affect their level of dietary contamination (Montiglio and Royauté, 2014). For instance, perch (Perca fluviatilis) exposed to psychiatric drugs were more active and bolder than control fish and had a lower latency to feed (Brodin et al., 2013). These pollution-induced behavioral changes increased their foraging rate on zooplankton in the water column, which is a prey item potentially carrying a high dose of accumulated drugs (Brodin et al., 2013, 2014). In addition, organisms exposed to pollutants generally have higher metabolic rates and greater energetic needs, because detoxifying and repair processes are costly (e.g., McKenzie et al., 2007), which could increase their activity and foraging, and hence their exposure to dietarytransmitted pollutants (Montiglio and Royauté, 2014). For instance, crucian carp Carassius carassius exposed to dietary polystyrene nanoparticles through the food chain had altered activity and higher feeding time, likely due to increased energetic needs and/or altered brain structure (Mattsson et al., 2015, 2017). This could thus increase their exposure to further pollution in the wild, but empirical approaches are now needed to test this assumption.

In summary, pollution-induced alterations of exploration, sociability, memory, learning, appetite, boldness, and 


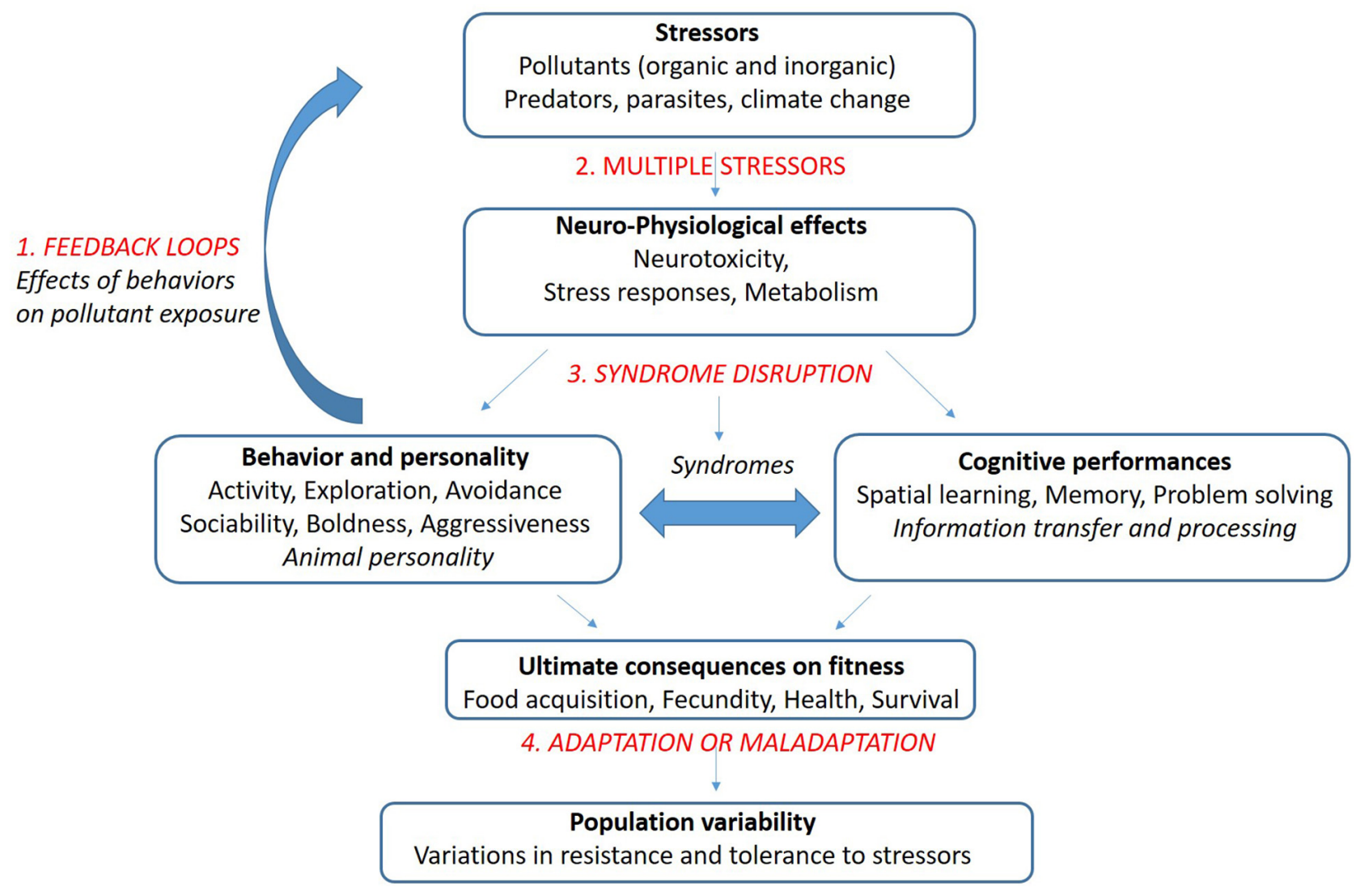

FIGURE 1 | Potential links between pollution, behavior and cognition, and proposed research perspectives (in red).

foraging could potentially in turn amplify fish exposure to environmentally or dietary contamination, and generate positive feedback loops (Montiglio and Royauté, 2014), with important implications for fish fitness. However, only indirect evidence exists so far, and further experimental studies are now needed to test this hypothesis.

\section{MULTIPLE STRESSOR EFFECTS ON BEHAVIOR AND FITNESS}

In addition, many behavioral disruptions caused by pollutants are amplified in the presence of additional abiotic and biotic stressors such as predators, parasites, or climate change. For instance, pollutants are likely to affect how efficiently individuals escape predators by altering activity, boldness, olfaction ability, and learning abilities (Weis et al., 1999, 2001; Lürling and Scheffer, 2007). Accordingly, copper impairs olfactory neurons in fathead minnow Pimephales promelas, which alters their ability to perceive alarm cues and increases their vulnerability to predation (Dew et al., 2014). In another study, banded tetra Astyanax aeneus exposed to an organophosphate pesticide had altered avoidance behavior and a lower ability to escape a predator attack (Sandoval-Herrera et al., 2019). As a result, the presence of predators can reveal the ecological effects of pollution on fish fitness through neuro-behavioral effects, resulting in lower fitness for individuals exposed to both pollution and predators.

Other biotic stressors such as parasites could also modulate the physiological and behavioral effects of pollutants. Indeed, resistance to pollutants and parasites are often based on shared neural and physiological pathways, which could result into significant interactions between these stressors (Thilakaratne et al., 2007; Blanar et al., 2009; Marcogliese and Pietrock, 2011). For instance, contaminants and parasites both involve important energetic, oxidative, and immune costs (e.g., Marcogliese et al., 2005), potentially leading to synergic or antagonistic effects depending on the metabolic strategy displayed (Sokolova et al., 2012; Sokolova, 2013; Petitjean et al., 2019). Pollution-exposed individuals generally invest more energy in costly detoxification processes (Du et al., 2018, 2019) at the expense of immunity (Dunier and Siwicki, 1993; Dunier, 1996), with potential consequences for parasite resistance (Arkoosh et al., 1991, 2001; Jansen et al., 2011; Rohr et al., 2013). For instance, three-spined stickleback Gasterosteus aculeatus exposed to a polymetallic stress were more susceptible to an immune challenge through changes in oxidative responses (Le Guernic et al., 2016). Parasites and their associated immune challenges could thus act as important biotic constraints altering the effects of pollution on fish behavior and fitness, but few studies experimentally tested this hypothesis, especially in fish. 
Other stressors such as climate change and water warming could also modulate the effects of pollutants, either through direct effects on the chemical properties of pollutants, and/or through complex interactive effects on neurophysiological pathways (Schiedek et al., 2007; Noyes et al., 2009). For instance, exposure to pesticides and water warming in goldfish had complex interactive effects on goldfish Carassius auratus proteome and cell integrity (Gandar et al., 2017b; Jacquin et al., 2019), and resulted in antagonistic effects on fish foraging activity in fish exposed to multiple stressors compared to fish exposed to single stressors (Gandar et al., 2015). To conclude, pollution effects often depend on the concomitant exposure to other biotic and abiotic stressors (Dinh Van et al., 2013, 2014; Tüzün et al., 2015, 2017; Debecker and Stoks, 2019; Saaristo et al., 2019), underlining the need for multistress approaches to better predict the cognitive and fitness consequences of pollution on wildlife.

\section{POLLUTION AS A REVEALING OR MASKING FACTOR OF BEHAVIORAL SYNDROMES}

Rather than being one-dimensional, animal personalities often consist of a suites of interrelated traits, referred to as behavioral syndromes (Sih et al., 2004; Réale et al., 2007; Conrad et al., 2011; Sih, 2011; Sih and Del Giudice, 2012). In fish, several consistent behavioral traits such as boldness, activity exploration, and sociability are linked together in syndromes, with important implications for fitness and evolutionary trajectories (Conrad et al., 2011; Dochtermann and Dingemanse, 2013). For instance, three-spined sticklebacks Gasterosteus aculeatus that are bolder and more aggressive are more likely to escape predator attacks and survive, resulting in higher fitness compared to other trait combinations (Bell and Sih, 2007; Dingemanse et al., 2007). Behavioral syndromes are also important for information use and learning. For instance, sticklebacks that are more prone to explore a maze have also a higher tendency to follow trained conspecifics, with potential advantages for social learning (Nomakuchi et al., 2009). It is thus important to take these syndromes into account because they could help predict the effects of stressors on fish fitness and cognition.

Various mechanisms could explain the links between traits, such as genetic linkage, correlational selection, resource allocation trade-offs, genetic or physiological pleiotropy (Houston and McNamara, 1999; Aubin-Horth et al., 2012; Killen et al., 2013). In fish, physiological traits and personality traits are tightly linked. For instance, lineages of trout selected for low stress responses have a lower production of cortisol and higher metabolic rate, but are also bolder, more aggressive, with a lower ability of reversal learning, compared to lineages selected for high stress responses (Overli et al., 2002; Höglund et al., 2017; Vindas et al., 2017). Stress responses and energetic adjustments linked to metabolism thus seem central constraints in determining syndrome structure and the links between stable behaviors in fish.

Because pollutants often trigger important stress responses and changes in metabolism, they have the potential to affect the structure of behavioral syndromes, with consequences for cognitive abilities and responses to environmental cues (Killen et al., 2013). In particular, pollution can trigger a stress response (cortisol production) that strongly affects energy status, energy acquisition and metabolism (Schreck et al., 2016). By triggering stress responses and enhancing the energetic demand, pollution could thus alter the energy allocation between traits, creating the potential for divergence in correlated physiology-behavior nexus (Killen et al., 2013).

On one hand, stressors could have revealing effects on syndromes by strengthening the links between traits (Killen et al., 2013). Accordingly, the anxiolytic oxazepam drug induced a correlation between boldness and activity in perch Perca fluviatilis, which was only present after exposure to the drug (Brodin et al., 2013). On the other hand, the adverse neurophysiological effects of stressors could limit the capacity of fish to express the full range of behaviors, and reduce the phenotypic variations observed, thereby masking any relationship between traits that was apparent under mild or single stressor exposure (Killen et al., 2013). In this case, stressors could have masking effects on syndromes by weakening any link between traits. For instance, fluoxetine decreased the behavioral correlations across contexts in Siamese fighting fish Betta splendens (Dzieweczynski et al., 2016). In other cases, stressors had no effects on behavioral nor physiological correlations, such as in damselflies Ischnura elegans exposed to zinc (Debecker and Stoks, 2019). The effects of pollution on syndromes are thus not clear yet and deserve further investigations. The existing literature suggest that pollutants indeed affect the structure of syndromes (i.e., the links between traits) by affecting the physiological-behavior nexus, but their specific effects seem to depend on the nature/dose/duration of stressors.

In addition, syndrome structure can be shaped by past natural selection, and have important implications for evolutionary trajectories. Indeed, natural selection could select for particular combinations of physiological, behavioral and cognitive traits (Conrad et al., 2011; Sih et al., 2012). For instance, predation favors the correlation between boldness and aggressiveness in Gasterosteus aculeatus populations coexisting with predators, because fish that are bolder and more aggressive are more likely to escape predators and survive (Bell and Sih, 2007; Dingemanse et al., 2007). It is also possible that pollution could select for particular trait combinations, but few studies tested this hypothesis (see Table 1). In addition, behavioral syndromes could have different evolutionary implications depending on the underlying mechanisms such as genetic correlations or physiological trade-offs (Bell and Aubin-Horth, 2010; Conrad et al., 2011; Dochtermann and Dingemanse, 2013). For instance, genetic correlations resulting from gene pleiotropy could potentially constrain the evolution of behavioral responses to pollutants. In this case, behavioral correlations would be relatively stable across environments, because such correlations will be difficult to break apart via selection (Dochtermann and Dingemanse, 2013). On the other hand, syndromes resulting from physiological trade-offs resulting from resource allocation could potentially change across environments, so that different trait combinations could be found in natural populations 
depending on levels of pollution, resource availability and/or other stressors (Bell and Aubin-Horth, 2010; Killen et al., 2013). However, there is currently a lack of knowledge on the underpinnings of behavioral correlations and syndromes in wild fish exposed to pollution and their implications for evolutionary trajectories (Conrad et al., 2011) (Table 1). Because syndrome structure could facilitate or impede opportunity for adaptive evolution (Sih et al., 2012; Dochtermann and Dingemanse, 2013), further studies testing the effects of pollution on behavioral syndromes are now necessary to refine our ability to predict the evolutionary effects of pollution on behavior.

\section{EVOLUTIONARY DIVERGENCE IN BEHAVIOR UNDER POLLUTION}

Interestingly, the burgeoning literature in evolutionary ecotoxicology has shown that some fish populations having evolved under chronic pollution have divergent response to an experimental contamination, suggesting local adaptation to pollutants (Bélanger-Deschênes et al., 2013; Oziolor et al., 2016; Brady et al., 2017). For instance, killifish Fundulus heteroclitus from highly contaminated environments have evolved geneticbased physiological ability to cope with organic pollutants (Reid et al., 2016; Whitehead et al., 2017). Some studies also investigated the divergence in behavior caused by pollution, but empirical evidence of behavioral local adaptation to pollution through genetic evolution and/or plasticity is still scarce. For instance, brown bullhead fish Ameiurus nebulosus from a polluted river had a higher aggressiveness than fish from an unpolluted river, but only $\mathrm{F} 0$ fish collected in the field were tested (Breckels and Neff, 2010). In this case, it is difficult to disentangle the genetic and plastic components of the observed behavioral divergence in F0 generation, which limits our ability to predict the consequences of pollution across generations. In another study, guppies Poecilia reticulata having evolved in Trinidadian rivers polluted by polycyclic aromatic hydrocarbons (PAHs) had a lower exploratory tendency compared to fish from unpolluted rivers after several generations raised in common garden conditions (F1 to F3 generations), suggesting genetic-based behavioral divergence among populations (Jacquin et al., 2017). However, other studies on the same model species showed little evidence of adaptive plasticity that would limit the deleterious effects of pollutants on fitness, especially in unpolluted environments (Rolshausen et al., 2015; Hamilton et al., 2017). This suggests that adaptation to pollution might be maladaptive in unpolluted environments, but more studies are now needed to disentangle the relative role of plasticity and genetic-based evolution in this potential maladaptation (Rolshausen et al., 2015; Hamilton et al., 2017; Brady et al., 2019).

In addition, the evolutionary effects of pollutants remain difficult to disentangle from other environmental stressors in the wild, maybe because multiple stressors might exert conflicting selective pressures (Jansen et al., 2011; Saaristo et al., 2018). Adaptation to a particular stressor (e.g., contamination) might for instance impede the adaptation to another stressor (e.g., parasite). Thus, adaptation to pollution might come at a cost, depending on additional stressors (e.g., Dutilleul et al., 2017). For instance, tolerance to pesticides is associated with increased susceptibility to diseases in some amphibians and crustaceans (e.g., Hua et al., 2017; Jansen et al., 2011). In the same vein, European flounder Platichthys flesus populations living in contaminated rivers display a lower tolerance to thermal stress, although the underlying mechanisms remain to be determined (Lavergne et al., 2015). On the other hand, some physiological adaptations to one stressor could confer advantages against additional stressors (co-tolerance, Vinebrooke et al., 2004). For instance, some families of Atlantic salmon Salmo salar that are tolerant to high-temperature are also more tolerant to hypoxia, because of increased heart ventricle size and myoglobin levels, although the evolutionary implications are still unclear (e.g., Anttila et al., 2013). In another study, some Daphnia magna populations are co-adapted to warming and increased toxicity (Zhang et al., 2018). However, most previous studies focused on physiological and life-history traits, so that the evolution of behavioral traits in a multiple stress framework remains unclear. It is possible that some behavioral and cognitive responses to pollution could bring fitness benefits in polluted environments, but come at a cost in other environments. For instance, we could hypothesize that decreased exploration caused by pollution (e.g., Jacquin et al., 2017; Grunst et al., 2018) could limit toxicant uptake in polluted areas, but have detrimental effects when food becomes scarce, because exploration brings benefits in terms of foraging (Reader, 2015). In other words, pollution might change the balance between costs and benefits of information processing in animals, but the expected outcome for fish fitness and evolutionary trajectories might depend on several environmental and social factors that remain to be investigated.

Finally, plasticity (and hence behavioral plasticity) generally plays an important role in evolutionary responses to anthropogenic conditions (Price et al., 2003; Ghalambor et al., 2007; Hendry et al., 2008; Sih et al., 2011). Behavioral changes could drive evolutionary changes by exposing individuals to new conditions (so-called "behavioral drive") or in the contrary limit evolutionary changes if plastic behavioral changes are sufficient to mitigate the fitness effects of pollution (Huey et al., 2003; Sol et al., 2005). Plastic behavioral responses to pollution could thus promote or impede genetic selection depending on environmental conditions, by facilitating or limiting the move from one adaptive peak (e.g., past unpolluted environment) to another adaptive peak (e.g., new polluted environment) in the adaptive landscape (Price et al., 2003; West-Eberhard, 2003; Ghalambor et al., 2007; Sih et al., 2011). However, some emerging pollutants such as new pesticides, pharmaceuticals, plastics, and nanoparticles are new chemicals that fish have never encountered in their environment in the past, so that polluted environments might represent evolutionary novel conditions. Past evolution is thus unlikely to generate suitable behavioral responses to pollution that could enhance fitness, although this might strongly depend on the species and on the type and dose of stressor (Sih et al., 2011). Pollution-induced behavioral changes could thus potentially generate maladaptive effects and generate evolutionary traps (Sih et al., 2011; Brady et al., 2019), but this hypothesis remains to be tested. 


\section{CONCLUSION}

To conclude, the existing literature underlines the need to take into account pollution and their associated behavioral, cognitive and fitness effects in a multistress context to better understand the complex responses of wild fish to pollution and their potential feedback loops. In addition, pollutants and multiple stressors can affect the physiology-behavior nexus and modify syndrome structure, which could generate interpopulation divergence in behavior and personality. Future work should now determine the evolutionary forces promoting such behavioral variability in the face of increasing pollution, and their implication for the evolutionary trajectories of wild populations. With this study, we hope to encourage future studies to bridge the gap between ecotoxicology, behavioral ecology and evolutionary ecology to better anticipate the effects of pollutants on evolutionary processes and population resilience in anthropized ecosystems.

\section{DATA AVAILABILITY STATEMENT}

All datasets generated for this study are included in the article/supplementary material.

\section{REFERENCES}

Anttila, K., Dhillon, R. S., Boulding, E. G., Farrell, A. P., Glebe, B. D., Elliott, J. A. K., et al. (2013). Variation in temperature tolerance among families of Atlantic salmon (Salmo salar) is associated with hypoxia tolerance, ventricle size and myoglobin level. J. Exp. Biol. 216, 1183-1190. doi: 10.1242/jeb.080556

Arkoosh, M. R., Casillas, E., Clemons, E., McCain, B., and Varanasi, U. (1991). Suppression of immunological memory in juvenile chinook salmon (Oncorhynchus tshawytscha) from an urban estuary. Fish Shellfish Immunol. 1, 261-277. doi: 10.1016/s1050-4648(05)80065-8

Arkoosh, M. R., Clemons, E., Huffman, P., Kagley, A. N., Casillas, E., Adams, N., et al. (2001). Increased susceptibility of juvenile chinook salmon to Vibriosis after exposure to chlorinated and aromatic compounds found in contaminated urban estuaries. J. Aquat. Anim. Health 13, 257-268. doi: 10.1577/15488667(2001)013<0257:isojcs > 2.0.co;2

Ashauer, R., Thorbek, P., Warinton, J. S., Wheeler, J. R., and Maund, S. (2013). A method to predict and understand fish survival under dynamic chemical stress using standard ecotoxicity data. Environ. Toxicol. Chem. 32, 954-965. doi: $10.1002 /$ etc. 2144

Atchison, G. J., Henry, M. G., and Sandheinrich, M. B. (1987). Effects of metals on fish behavior: a review. Environ. Biol. Fishes 18, 11-25. doi: 10.1007/ BF00002324

Aubin-Horth, N., Deschênes, M., and Cloutier, S. (2012). Natural variation in the molecular stress network correlates with a behavioural syndrome. Horm. Behav. 61, 140-146. doi: 10.1016/j.yhbeh.2011.11.008

Baatrup, E., and Junge, M. (2001). Antiandrogenic pesticides disrupt sexual characteristics in the adult male guppy Poecilia reticulata. Environ. Health Perspect. 109, 1063-1070. doi: 10.1289/ehp.011091063

Bayley, M., Nielsen, J. R., and Baatrup, E. (1999). Guppy sexual behavior as an effect biomarker of estrogen mimics. Ecotoxicol. Environ. Saf. 43, 68-73. doi: 10.1006/eesa.1999.1766

Beauvais, S. L., Jones, S. B., Parris, J. T., Brewer, S. K., and Little, E. E. (2001). Cholinergic and behavioral neurotoxicity of carbaryl and cadmium to larval rainbow trout (Oncorhynchus mykiss). Ecotoxicol. Environ. Saf. 49, 84-90. doi: 10.1006/eesa.2000.2032

Bélanger-Deschênes, S., Couture, P., Campbell, P. G. C., and Bernatchez, L. (2013). Evolutionary change driven by metal exposure as revealed by coding SNP

\section{AUTHOR CONTRIBUTIONS}

LJ drafted the initial version of the manuscript. All authors contributed to the writing and revising of the manuscript.

\section{FUNDING}

This work was supported by a grant from Agence de l'Eau Adour-Garonne (PHYPAT project), the CNRS EC2CO ECODYN program, the ZA PYGAR (CNRS) and the CPER ECONAT. The EDB laboratory is part of the Laboratory of Excellence "TULIP" (ANR-10-LABX-41; ANR-11-IDEX-0002-02).

\section{ACKNOWLEDGMENTS}

We thank the reviewers for their constructive comments. We also thank Annie Perrault, Myriam Cousseau, Louna Riem, Emilie Rojas, Flavien Garcia, Aurélie Goutte, Stéphane Bétoulle, Simon Blanchet, and Géraldine Loot for assistance and discussions at different stages of this study.

genome scan in wild yellow perch (Perca flavescens). Ecotoxicology 22, 938-957. doi: $10.1007 / \mathrm{s} 10646-013-1083-8$

Bell, A. M., and Aubin-Horth, N. (2010). What can whole genome expression data tell us about the ecology and evolution of personality? Philos. Trans. R. Soc. Lond. B Biol. Sci. 365, 4001-4012. doi: 10.1098/rstb.2010. 0185

Bell, A. M., and Sih, A. (2007). Exposure to predation generates personality in threespined sticklebacks (Gasterosteus aculeatus). Ecol. Lett. 10, 828-834. doi: 10.1111/j.1461-0248.2007.01081.x

Bertram, M. G., Saaristo, M., Baumgartner, J. B., Johnstone, C. P., Allinson, M., Allinson, G., et al. (2015). Sex in troubled waters: widespread agricultural contaminant disrupts reproductive behaviour in fish. Horm. Behav. 70, 85-91. doi: 10.1016/j.yhbeh.2015.03.002

Blanar, C. A., Munkittrick, K. R., Houlahan, J., MacLatchy, D. L., and Marcogliese, D. J. (2009). Pollution and parasitism in aquatic animals: a meta-analysis of effect size. Aquat. Toxicol. 93, 18-28. doi: 10.1016/j.aquatox.2009.03.002

Brady, S. P., Bolnick, D. I., Angert, A. L., Gonzalez, A., Barrett, R. D. H., Crispo, E., et al. (2019). Causes of maladaptation. Evol. Appl. 12, 1229-1242. doi: 10.1111/ eva. 12844

Brady, S. P., Richardson, J. L., and Kunz, B. K. (2017). Incorporating evolutionary insights to improve ecotoxicology for freshwater species. Evol. Appl. 10, 829838. doi: 10.1111/eva.12507

Braunbeck, A., Streit, A., and Hinton, A. (eds) (2013). Fish Ecotoxicology. Basel Birkhäuser: Birkhäuser Verlag.

Breckels, R. D., and Neff, B. D. (2010). Pollution-induced behavioural effects in the brown bullhead (Ameiurus nebulosus). Ecotoxicology 19, 1337-1346. doi: 10.1007/s10646-010-0520-1

Bridi, D., Altenhofen, S., Gonzalez, J. B., Reolon, G. K., and Bonan, C. D. (2017). Glyphosate and Roundup ${ }^{\circledR}$ alter morphology and behavior in zebrafish. Toxicology 392, 32-39. doi: 10.1016/j.tox.2017.10.007

Brodin, T., Fick, J., Jonsson, M., and Klaminder, J. (2013). Dilute concentrations of a psychiatric drug alter behavior of fish from natural populations. Science 339, 814-815. doi: 10.1126/science. 1226850

Brodin, T., Piovano, S., Fick, J., Klaminder, J., Heynen, M., and Jonsson, M. (2014). Ecological effects of pharmaceuticals in aquatic systems-impacts through behavioural alterations. Philos. Trans. R. Soc. Lond. B Biol. Sci. 369:20130580. doi: $10.1098 /$ rstb.2013.0580 
Brown, T., Laland, D. E., and Krause, D. (eds) (2006). Fish Cognition and Behavior, 1st Edn. Hoboken, NJ: Wiley-Blackwell.

Brown, C., and Laland, K. N. (2003). Social learning in fishes: a review. Fish Fish. 4, 280-288. doi: 10.1046/j.1467-2979.2003.00122.x

Butcher, J., Diamond, J., Bearr, J., Latimer, H., Klaine, S. J., Hoang, T., et al. (2006). Toxicity models of pulsed copper exposure to Pimephales promelas and Daphnia magna. Environ. Toxicol. Chem. 25, 2541-2550. doi: 10.1897/05630R.1

Clotfelter, E. D., Bell, A. M., and Levering, K. R. (2004). The role of animal behaviour in the study of endocrine-disrupting chemicals. Anim. Behav. 68, 665-676. doi: 10.1016/j.anbehav.2004.05.004

Conrad, J. L., Weinersmith, K. L., Brodin, T., Saltz, J. B., and Sih, A. (2011). Behavioural syndromes in fishes: a review with implications for ecology and fisheries management. J. Fish Biol. 78, 395-435. doi: 10.1111/j.1095-8649.2010. 02874.x

Couillard, C. M., Légaré, B., Bernier, A., and Dionne, Z. (2011). Embryonic exposure to environmentally relevant concentrations of PCB126 affect prey capture ability of Fundulus heteroclitus larvae. Mar. Environ. Res. 71, 257-265. doi: 10.1016/j.marenvres.2011.01.010

Critchell, K., and Hoogenboom, M. O. (2018). Effects of microplastic exposure on the body condition and behaviour of planktivorous reef fish (Acanthochromis polyacanthus). PLoS One 13:e0193308. doi: 10.1371/journal.pone.0193308

de Castro, M. R., Lima, J. V., Salomão de Freitas, D. P., de Souza Valente, R., Dummer, N. S., de Aguiar, R. B., et al. (2009). Behavioral and neurotoxic effects of arsenic exposure in zebrafish (Danio rerio, Teleostei: Cyprinidae). Comp. Biochem. Physiol. C Toxicol. Pharmacol. 150, 337-342. doi: 10.1016/j.cbpc.2009.05.017

Debecker, S., and Stoks, R. (2019). Pace of life syndrome under warming and pollution: integrating life history, behavior, and physiology across latitudes. Ecol. Monogr. 89:e01332. doi: 10.1002/ecm.1332

Dew, W. A., Azizishirazi, A., and Pyle, G. G. (2014). Contaminant-specific targeting of olfactory sensory neuron classes: connecting neuron class impairment with behavioural deficits. Chemosphere 112, 519-525. doi: 10.1016/j.chemosphere. 2014.02.047

Dingemanse, N. J., Wright, J., Kazem, A. J. N., Thomas, D. K., Hickling, R., and Dawnay, N. (2007). Behavioural syndromes differ predictably between 12 populations of three-spined stickleback. J. Anim. Ecol. 76, 1128-1138. doi: 10.1111/j.1365-2656.2007.01284.x

Dinh Van, K., Janssens, L., Debecker, S., De Jonge, M., Lambret, P., NilssonÖrtman, V., et al. (2013). Susceptibility to a metal under global warming is shaped by thermal adaptation along a latitudinal gradient. Glob. Chang. Biol. 19, 2625-2633. doi: $10.1111 / \mathrm{gcb} .12243$

Dinh Van, K., Janssens, L., Debecker, S., and Stoks, R. (2014). Warming increases chlorpyrifos effects on predator but not anti-predator behaviours. Aquat. Toxicol. 152, 215-221. doi: 10.1016/j.aquatox.2014.04.011

Dochtermann, N. A., and Dingemanse, N. J. (2013). Behavioral syndromes as evolutionary constraints. Behav. Ecol. 24, 806-811. doi: 10.1093/beheco/art002

Du, S. N. N., Choi, J. A., McCallum, E. S., McLean, A. R., Borowiec, B. G., Balshine, S., et al. (2019). Metabolic implications of exposure to wastewater effluent in bluegill sunfish. Comp. Biochem. Physiol. C Toxicol. Pharmacol. 224:108562. doi: 10.1016/j.cbpc.2019.108562

Du, S. N. N., McCallum, E. S., Vaseghi-Shanjani, M., Choi, J. A., Warriner, T. R., Balshine, S., et al. (2018). Metabolic costs of exposure to wastewater effluent lead to compensatory adjustments in respiratory physiology in bluegill sunfish. Environ. Sci. Technol. 52, 801-811. doi: 10.1021/acs.est.7b03745

Dunier, M. (1996). Water pollution and immunosuppression of freshwater fish. Ital. J. Zool. 63, 303-309. doi: 10.1080/11250009609356150

Dunier, M., and Siwicki, A. K. (1993). Effects of pesticides and other organic pollutants in the aquatic environment on immunity of fish: a review. Fish Shellfish Immunol. 3, 423-438. doi: 10.1006/fsim.1993.1042

Dutilleul, M., Réale, D., Goussen, B., Lecomte, C., Galas, S., and Bonzom, J.-M. (2017). Adaptation costs to constant and alternating polluted environments. Evol. Appl. 10, 839-851. doi: 10.1111/eva.12510

Dzieweczynski, T. L., Campbell, B. A., Marks, J. M., and Logan, B. (2014). Acute exposure to $17 \alpha$-ethinylestradiol alters boldness behavioral syndrome in female Siamese fighting fish. Horm. Behav. 66, 577-584. doi: 10.1016/j.yhbeh.2014.08. 005
Dzieweczynski, T. L., Kane, J. L., Campbell, B. A., and Lavin, L. E. (2016). Fluoxetine exposure impacts boldness in female Siamese fighting fish, Betta splendens. Ecotoxicology 25, 69-79. doi: 10.1007/s10646-015-1568-8

Dzieweczynski, T. L., Portrais, K. B., Stevens, M. A., Kane, J. L., and Lawrence, J. M. (2018). Risky business: changes in boldness behavior in male Siamese fighting fish. Betta splendens, following exposure to an antiandrogen. Environ. Pollut. 235, 1015-1021. doi: 10.1016/j.envpol.2018.01.029

Eisenreich, B. R., Greene, S., and Szalda-Petree, A. (2017). Of fish and mirrors: Fluoxetine disrupts aggression and learning for social rewards. Physiol. Behav. 173, 258-262. doi: 10.1016/j.physbeh.2017.02.021

Eisenreich, B. R., and Szalda-Petree, A. (2015). Behavioral effects of fluoxetine on aggression and associative learning in Siamese fighting fish (Betta splendens). Behav. Processes 121, 37-42. doi: 10.1016/j.beproc.2015.10.008

Gandar, A., Jean, S., Canal, J., Marty-Gasset, N., Gilbert, F., and Laffaille, P. (2015). Multistress effects on goldfish (Carassius auratus) behavior and metabolism. Environ. Sci. Pollut. Res. 23, 3184-3194. doi: 10.1007/s11356-015-5147-6

Gandar, A., Laffaille, P., Canlet, C., Tremblay-Franco, M., Gautier, R., Perrault, A., et al. (2017a). Adaptive response under multiple stress exposure in fish: from the molecular to individual level. Chemosphere 188, 60-72. doi: 10.1016/j. chemosphere.2017.08.089

Gandar, A., Laffaille, P., Marty-Gasset, N., Viala, D., Molette, C., and Jean, S. (2017b). Proteome response of fish under multiple stress exposure: effects of pesticide mixtures and temperature increase. Aquat. Toxicol. 184, 61-77. doi: 10.1016/j.aquatox.2017.01.004

Ghalambor, C. K., McKay, J. K., Carroll, S. P., and Reznick, D. N. (2007). Adaptive versus non-adaptive phenotypic plasticity and the potential for contemporary adaptation in new environments. Funct. Ecol. 21, 394-407. doi: 10.1111/j.13652435.2007.01283.x

Giaquinto, P. C., de Sá, M. B., Sugihara, V. S., Gonçalves, B. B., Delício, H. C., and Barki, A. (2017). Effects of glyphosate-based herbicide sub-lethal concentrations on fish feeding behavior. Bull. Environ. Contam. Toxicol. 98, 460-464. doi: 10.1007/s00128-017-2037-2

Giulio, R. T. D., and Hinton, D. E. (2008). The Toxicology of Fishes. Boca Raton, FL: CRC Press.

Grassie, C., Braithwaite, V. A., Nilsson, J., Nilsen, T. O., Teien, H.-C., Handeland, S. O., et al. (2013). Aluminum exposure impacts brain plasticity and behavior in Atlantic salmon (Salmo salar). J. Exp. Biol. 216, 3148-3155. doi: 10.1242/jeb. 083550

Grunst, A. S., Grunst, M. L., Daem, N., Pinxten, R., Bervoets, L., and Eens, M. (2019). An important personality trait varies with blood and plumage metal concentrations in a free-living songbird. Environ. Sci. Technol. 53, 1048710496. doi: 10.1021/acs.est.9b03548

Grunst, A. S., Grunst, M. L., Thys, B., Raap, T., Daem, N., Pinxten, R., et al. (2018). Variation in personality traits across a metal pollution gradient in a free-living songbird. Sci. Total Environ. 630, 668-678. doi: 10.1016/j.scitotenv.2018.02.191

Hamilton, P. B., Rolshausen, G., Uren Webster, T. M., and Tyler, C. R. (2017). Adaptive capabilities and fitness consequences associated with pollution exposure in fish. Philos. Trans. R. Soc. Lond. B Biol. Sci. 372:20160042. doi: 10.1098/rstb.2016.0042

Hellström, G., Klaminder, J., Finn, F., Persson, L., Alanärä, A., Jonsson, M., et al. (2016). GABAergic anxiolytic drug in water increases migration behaviour in salmon. Nat. Commun. 7:13460 doi: 10.1038/ncomms13460

Hendry, A. P., Farrugia, T. J., and Kinnison, M. T. (2008). Human influences on rates of phenotypic change in wild animal populations. Mol. Ecol. 17, 20-29. doi: 10.1111/j.1365-294X.2007.03428.x

Hernández-Moreno, D., Pérez-López, M., Soler, F., Gravato, C., and Guilhermino, L. (2011). Effects of carbofuran on the sea bass (Dicentrarchus labrax L.): study of biomarkers and behaviour alterations. Ecotoxicol. Environ. Saf. 74, 1905-1912. doi: 10.1016/j.ecoenv.2011.07.016

Höglund, E., Silva, P. I. M., Vindas, M. A., and Øverli, Ø. (2017). Contrasting coping styles meet the wall: a dopamine driven dichotomy in behavior and cognition. Front. Neurosci. 11:383. doi: 10.3389/fnins.2017.00383

Hong, X., and Zha, J. (2019). Fish behavior: a promising model for aquatic toxicology research. Sci. Total Environ. 686, 311-321. doi: 10.1016/j.scitotenv. 2019.06.028

Houston, A. I., and McNamara, J. M. (1999). Models of Adaptive Behaviour: An Approach Based on State. Cambridge: Cambridge University Press. 
Hua, J., Wuerthner, V. P., Jones, D. K., Mattes, B., Cothran, R. D., Relyea, R. A., et al. (2017). Evolved pesticide tolerance influences susceptibility to parasites in amphibians. Evol. Appl. 10, 802-812. doi: 10.1111/eva.12500

Huey, R. B., Hertz, P. E., and Sinervo, B. (2003). Behavioral drive versus behavioral inertia in evolution: a null model approach. Am. Nat. 161, 357-366. doi: 10. $1086 / 346135$

Jacquin, L., Dybwad, C., Rolshausen, G., Hendry, A. P., and Reader, S. M. (2017). Evolutionary and immediate effects of crude-oil pollution: depression of exploratory behaviour across populations of Trinidadian guppies. Anim. Cogn. 20, 97-108. doi: 10.1007/s10071-016-1027-9

Jacquin, L., Gandar, A., Aguirre-Smith, M., Perrault, A., Hénaff, M. L., Jong, L. D., et al. (2019). High temperature aggravates the effects of pesticides in goldfish. Ecotoxicol. Environ. Saf. 172, 255-264. doi: 10.1016/j.ecoenv.2019. 01.085

Jansen, M., Stoks, R., Coors, A., van Doorslaer, W., and de Meester, L. (2011). Collateral damage: rapid exposure-induced evolution of pesticide resistance leads to increased susceptibility to parasites. Evolution 65, 2681-2691. doi: 10.1111/j.1558-5646.2011.01331.x

Killen, S. S., Marras, S., Metcalfe, N. B., McKenzie, D. J., and Domenici, P. (2013). Environmental stressors alter relationships between physiology and behaviour. Trends Ecol. Evol. 28, 651-658. doi: 10.1016/j.tree.2013.05.005

Klaminder, J., Jonsson, M., Leander, J., Fahlman, J., Brodin, T., Fick, J., et al. (2019). Less anxious salmon smolt become easy prey during downstream migration. Sci. Total Environ. 687, 488-493. doi: 10.1016/j.scitotenv.2019.05.488

Kohlert, J. G., Mangan, B. P., Kodra, C., Drako, L., Long, E., and Simpson, H. (2012). Decreased aggressive and locomotor behaviors in Betta splendens after exposure to fluoxetine. Psychol. Rep. 110, 51-62. doi: 10.2466/02.13.pr0.110.1. 51-62

Kolok, A. S., Plaisance, E. P. P., and Abdelghani, A. (1998). Individual variation in the swimming performance of fishes: an overlooked source of variation in toxicity studies. Environ. Toxicol. Chem. 17, 282-285. doi: 10.1002/etc. 5620170221

Kristensen, T., Baatrup, E., and Bayley, M. (2005). 17 $\alpha$-Ethinylestradiol reduces the competitive reproductive fitness of the male guppy (Poecilia reticulata) 1. Biol. Reprod. 72, 150-156. doi: 10.1095/biolreprod.104.033001

Laland, K. N., and Williams, K. (1997). Shoaling generates social learning of foraging information in guppies. Anim. Behav. 53, 1161-1169. doi: 10.1006/ anbe. 1996.0318

Lavergne, E., Pedron, N., Calves, I., Claireaux, G., Mazurais, D., ZamboninoInfante, J., et al. (2015). Does the chronic chemical contamination of a European flounder population decrease its thermal tolerance? Mar. Pollut. Bull. 95, 658-664. doi: 10.1016/j.marpolbul.2015.01.006

Le Guernic, A., Sanchez, W., Palluel, O., Bado-Nilles, A., Floriani, M., Turies, C., et al. (2016). Acclimation capacity of the three-spined stickleback (Gasterosteus aculeatus, L.) to a sudden biological stress following a polymetallic exposure. Ecotoxicology. 25, 1478-1499. doi: 10.1007/s10646-016-1699-6

Levin, E. D., Chrysanthis, E., Yacisin, K., and Linney, E. (2003). Chlorpyrifos exposure of developing zebrafish: effects on survival and long-term effects on response latency and spatial discrimination. Neurotoxicol. Teratol. 25, 51-57. doi: 10.1016/s0892-0362(02)00322-7

Little, E. E., Archeski, R. D., Flerov, B. A., and Kozlovskaya, V. I. (1990). Behavioral indicators of sublethal toxicity in rainbow trout. Arch. Environ. Contam. Toxicol. 19, 380-385. doi: 10.1007/bf01054982

Lürling, M., and Scheffer, M. (2007). Info-disruption: pollution and the transfer of chemical information between organisms. Trends Ecol. Evol. 22, 374-379. doi: 10.1016/j.tree.2007.04.002

Marcogliese, D., Brambilla, L., Gagné, F., and Gendron, A. (2005). Joint effects of parasitism and pollution on oxidative stress biomarkers in yellow perch Perca flavescens. Dis. Aquat. Organ. 63, 77-84. doi: 10.3354/dao063077

Marcogliese, D. J., and Pietrock, M. (2011). Combined effects of parasites and contaminants on animal health: parasites do matter. Trends Parasitol. 27, 123-130. doi: 10.1016/j.pt.2010.11.002

Martin, J. M., Saaristo, M., Bertram, M. G., Lewis, P. J., Coggan, T. L., Clarke, B. O., et al. (2017). The psychoactive pollutant fluoxetine compromises antipredator behaviour in fish. Environ. Pollut. 222, 592-599. doi: 10.1016/j.envpol.2016.10. 010

Mattsson, K., Ekvall, M. T., Hansson, L.-A., Linse, S., Malmendal, A., and Cedervall, T. (2015). Altered behavior, physiology, and metabolism in fish exposed to polystyrene nanoparticles. Environ. Sci. Technol. 49, 553-561. doi: 10.1021/ es5053655

Mattsson, K., Johnson, E. V., Malmendal, A., Linse, S., Hansson, L.-A., and Cedervall, T. (2017). Brain damage and behavioural disorders in fish induced by plastic nanoparticles delivered through the food chain. Sci. Rep. 7:11452. doi: 10.1038/s41598-017-10813-0

Maximino, C., Araujo, J., Leão, L. K. R., Grisolia, A. B. A., Oliveira, K. R. M., Lima, M. G., et al. (2011). Possible role of serotoninergic system in the neurobehavioral impairment induced by acute methylmercury exposure in zebrafish (Danio rerio). Neurotoxicol. Teratol. 33, 727-734. doi: 10.1016/j.ntt. 2011.08.006

McCallum, E. S., Du, S. N. N., Vaseghi-Shanjani, M., Choi, J. A., Warriner, T. R., Sultana, T., et al. (2017). In situ exposure to wastewater effluent reduces survival but has little effect on the behaviour or physiology of an invasive Great Lakes fish. Aquat. Toxicol. 184, 37-48. doi: 10.1016/j.aquatox.2016. 12.017

McCallum, E. S., Sundelin, A., Fick, J., Alanärä, A., Klaminder, J., Hellström, G., et al. (2019). Investigating tissue bioconcentration and the behavioural effects of two pharmaceutical pollutants on sea trout (Salmo trutta) in the laboratory and field. Aquat. Toxicol. 207, 170-178. doi: 10.1016/j.aquatox.2018.11.028

McKenzie, D. J., Garofalo, E., Winter, M. J., Ceradini, S., Verweij, F., Day, N., et al. (2007). Complex physiological traits as biomarkers of the sub-lethal toxicological effects of pollutant exposure in fishes. Philos. Trans. R. Soc. B Biol. Sci. 362, 2043-2059. doi: 10.1098/rstb.2007.2100

Montiglio, P.-O., and Royauté, R. (2014). Contaminants as a neglected source of behavioural variation. Anim. Behav. 88, 29-35. doi: 10.1016/j.anbehav.2013.11. 018

Nomakuchi, S., Park, P. J., and Bell, M. A. (2009). Correlation between exploration activity and use of social information in three-spined sticklebacks. Behav. Ecol. 20, 340-345. doi: 10.1093/beheco/arp001

Noyes, P. D., McElwee, M. K., Miller, H. D., Clark, B. W., Van Tiem, L. A., Walcott, K. C., et al. (2009). The toxicology of climate change: environmental contaminants in a warming world. Environ. Int. 35, 971-986. doi: 10.1016/j. envint.2009.02.006

Ososkov, I., and Weis, J. S. (1996). Development of social behavior in larval mummichogs after embryonic exposure to methylmercury. Trans. Am. Fish. Soc. 125, 983-987. doi: 10.1577/1548-8659(1996)125<0983:dosbil>2.3.co;2

Ostrander, G. K., Landolt, M. L., and Kocan, R. M. (1988). The ontogeny of coho salmon (Oncorhynchus kisutch) behavior following embryonic exposure to benzo[a]pyrene. Aquat. Toxicol. 13, 325-346. doi: 10.1016/0166-445x(88) 90153-1

Overli, O., Pottinger, T. G., Carrick, T. R., Overli, E., and Winberg, S. (2002). Differences in behaviour between rainbow trout selected for high- and lowstress responsiveness. J. Exp. Biol. 205, 391-395.

Oziolor, E. M., De Schamphelaere, K., and Matson, C. W. (2016). Evolutionary toxicology: meta-analysis of evolutionary events in response to chemical stressors. Ecotoxicology 25, 1858-1866. doi: 10.1007/s10646-0161735-6

Petitjean, Q., Jean, S., Gandar, A., Côte, J., Laffaille, P., and Jacquin, L. (2019). Stress responses in fish: from molecular to evolutionary processes. Sci. Total Environ. 684, 371-380. doi: 10.1016/j.scitotenv.2019.05.357

Powers, C. M., Levin, E. D., Seidler, F. J., and Slotkin, T. A. (2011). Silver exposure in developing Zebrafish produces persistent synaptic and behavioral changes. Neurotoxicol. Teratol. 33, 329-332. doi: 10.1016/j.ntt.2010. 10.006

Price, T. D., Qvarnström, A., and Irwin, D. E. (2003). The role of phenotypic plasticity in driving genetic evolution. Proc. R. Soc. Lond. B Biol. Sci. 270, 1433-1440.

Reader, S. M. (2015). Causes of individual differences in animal exploration and search. Top. Cogn. Sci. 7, 451-468. doi: 10.1111/tops.12148

Réale, D., Dingemanse, N. J., Kazem, A. J. N., and Wright, J. (2010). Evolutionary and ecological approaches to the study of personality. Philos. Trans. R. Soc. B 365, 3937-3946. doi: 10.1098/rstb.2010.0222

Réale, D., Reader, S. M., Sol, D., McDougall, P. T., and Dingemanse, N. J. (2007). Integrating animal temperament within ecology and evolution. Biol. Rev. 82, 291-318. doi: 10.1111/j.1469-185X.2007.00010.x

Reid, N. M., Proestou, D. A., Clark, B. W., Warren, W. C., Colbourne, J. K., Shaw, J. R., et al. (2016). The genomic landscape of rapid repeated evolutionary 
adaptation to toxic pollution in wild fish. Science 354, 1305-1308. doi: 10.1126/ science.aah4993

Robinson, P. D. (2009). Behavioural toxicity of organic chemical contaminants in fish: application to ecological risk assessments (ERAs). Can. J. Fish. Aquat. Sci. 66, 1179-1188. doi: 10.1139/F09-069

Rohr, J. R., Raffel, T. R., Halstead, N. T., McMahon, T. A., Johnson, S. A., Boughton, R. K., et al. (2013). Early-life exposure to a herbicide has enduring effects on pathogen-induced mortality. Proc. Biol. Sci. 280:20140629. doi: 10.1098/rspb. 2013.1502

Rolshausen, G., Phillip, D. A. T., Beckles, D. M., Akbari, A., Ghoshal, S., Hamilton, P. B., et al. (2015). Do stressful conditions make adaptation difficult? Guppies in the oil-polluted environments of southern Trinidad. Evol. Appl. 8, 854-870. doi: 10.1111/eva.12289

Saaristo, M., Brodin, T., Balshine, S., Bertram, M. G., Brooks, B. W., Ehlman, S. M., et al. (2018). Direct and indirect effects of chemical contaminants on the behaviour, ecology and evolution of wildlife. Proc. Biol. Sci. 285:20181297. doi: 10.1098/rspb.2018.1297

Saaristo, M., Lagesson, A., Bertram, M. G., Fick, J., Klaminder, J., Johnstone, C. P., et al. (2019). Behavioural effects of psychoactive pharmaceutical exposure on European perch (Perca fluviatilis) in a multi-stressor environment. Sci. Total Environ. 655, 1311-1320. doi: 10.1016/j.scitotenv.2018. 11.228

Saaristo, M., McLennan, A., Johnstone, C. P., Clarke, B. O., and Wong, B. B. M. (2017). Impacts of the antidepressant fluoxetine on the anti-predator behaviours of wild guppies (Poecilia reticulata). Aquat. Toxicol. 183, 38-45. doi: 10.1016/j.aquatox.2016.12.007

Sandoval-Herrera, N., Mena, F., Espinoza, M., and Romero, A. (2019). Neurotoxicity of organophosphate pesticides could reduce the ability of fish to escape predation under low doses of exposure. Sci. Rep. 9:10530. doi: 10.1038/ s41598-019-46804-6

Schiedek, D., Sundelin, B., Readman, J. W., and Macdonald, R. W. (2007). Interactions between climate change and contaminants. Mar. Pollut. Bull. 54, 1845-1856. doi: 10.1016/j.marpolbul.2007.09.020

Schinegger, R., Palt, M., Segurado, P., and Schmutz, S. (2016). Untangling the effects of multiple human stressors and their impacts on fish assemblages in European running waters. Sci. Total Environ. 573, 1079-1088. doi: 10.1016/j. scitotenv.2016.08.143

Scholz, N. L., Truelove, N. K., French, B. L., Berejikian, B. A., Quinn, T. P., Casillas, E., et al. (2000). Diazinon disrupts antipredator and homing behaviors in chinook salmon (Oncorhynchus tshawytscha). Can. J. Fish. Aquatic. Sci. 57, 1911-1918. doi: 10.1139/f00- 147

Schreck, C. B., Tort, L., Farrell, A. P., and Brauner, C. J. (eds) (2016). "Biology of Stress in Fish," in Fish Physiology (Amsterdam: Academic Press).

Scott, G. R., and Sloman, K. A. (2004). The effects of environmental pollutants on complex fish behaviour: integrating behavioural and physiological indicators of toxicity. Aquat. Toxicol. 68, 369-392. doi: 10.1016/j.aquatox.2004. 03.016

Shinn, C., Santos, M. M., Lek, S., and Grenouillet, G. (2015). Behavioral response of juvenile rainbow trout exposed to an herbicide mixture. Ecotoxicol. Environ. Saf. 112, 15-21. doi: 10.1016/j.ecoenv.2014.10.013

Sih, A. (2011). Effects of early stress on behavioral syndromes: an integrated adaptive perspective. Neurosci. Biobehav. Rev. 35, 1452-1465. doi: 10.1016/j. neubiorev.2011.03.015

Sih, A., Bell, A., and Johnson, J. C. (2004). Behavioral syndromes: an ecological and evolutionary overview. Trends Ecol. Evol. 19, 372-378. doi: 10.1016/j.tree.2004. 04.009

Sih, A., Cote, J., Evans, M., Fogarty, S., and Pruitt, J. (2012). Ecological implications of behavioural syndromes: ecological implications of behavioural syndromes. Ecol. Lett. 15, 278-289. doi: 10.1111/j.1461-0248.2011.01731.x

Sih, A., and Del Giudice, M. (2012). Linking behavioural syndromes and cognition: a behavioural ecology perspective. Philos. Trans. R. Soc. B Biol. Sci. 367, 2762-2772. doi: $10.1098 /$ rstb.2012.0216

Sih, A., Ferrari, M. C. O., and Harris, D. J. (2011). Evolution and behavioural responses to human-induced rapid environmental change: behaviour and evolution. Evol. Appl. 4, 367-387. doi: 10.1111/j.1752-4571.2010.00166.x

Sloman, K. A., and McNeil, P. L. (2012). Using physiology and behaviour to understand the responses of fish early life stages to toxicants. J. Fish Biol. 81, 2175-2198. doi: 10.1111/j.1095-8649.2012.03435.x
Sloman, K. A., Scott, G. R., Diao, Z., Rouleau, C., Wood, C. M., and McDonald, D. G. (2003). Cadmium affects the social behaviour of rainbow trout, Oncorhynchus mykiss. Aquat. Toxicol. 65, 171-185. doi: 10.1016/S0166445X(03)00122-X

Smith, L. E., Carvan, M. J., Dellinger, J. A., Ghorai, J. K., White, D. B., Williams, F. E., et al. (2010). Developmental selenomethionine and methylmercury exposures affect zebrafish learning. Neurotoxicol. Teratol. 32, 246-255. doi: 10.1016/j.ntt.2009.09.004

Sokolova, I. M. (2013). Energy-limited tolerance to stress as a conceptual framework to integrate the effects of multiple stressors. Integr. Comp. Biol. 53, 597-608. doi: 10.1093/icb/ict028

Sokolova, I. M., Frederich, M., Bagwe, R., Lannig, G., and Sukhotin, A. A. (2012). Energy homeostasis as an integrative tool for assessing limits of environmental stress tolerance in aquatic invertebrates. Mar. Environ. Res. 79, 1-15. doi: 10. 1016/j.marenvres.2012.04.003

Sol, D., Stirling, D. G., and Lefebvre, L. (2005). Behavioral drive or behavioral inhibition in evolution: subspecific diversification in holarctic passerines. Evolution 59, 2669-2677. doi: 10.1111/j.0014-3820.2005.tb0 0978.x

Sopinka, N. M., Marentette, J. R., and Balshine, S. (2010). Impact of contaminant exposure on resource contests in an invasive fish. Behav. Ecol. Sociobiol. 64 , 1947-1958. doi: 10.1007/s00265-010-1005-1

Thilakaratne, I. D. S. I. P., McLaughlin, J. D., and Marcogliese, D. J. (2007). Effects of pollution and parasites on biomarkers of fish health in spottail shiners Notropis hudsonius (Clinton). J. Fish Biol. 71, 519-538. doi: 10.1111/j.10958649.2007.01511.x

Timme-Laragy, A. R., Levin, E. D., and Di Giulio, R. T. (2006). Developmental and behavioral effects of embryonic exposure to the polybrominated diphenylether mixture DE-71 in the killifish (Fundulus heteroclitus). Chemosphere 62, 10971104. doi: 10.1016/j.chemosphere.2005.05.037

Tomkins, P., Saaristo, M., Bertram, M. G., Michelangeli, M., Tomkins, R. B., and Wong, B. B. M. (2018). An endocrine-disrupting agricultural contaminant impacts sequential female mate choice in fish. Environ. Pollut. 237, 103-110. doi: 10.1016/j.envpol.2018.02.046

Tosetto, L., Williamson, J. E., and Brown, C. (2017). Trophic transfer of microplastics does not affect fish personality. Anim. Behav. 123, 159-167. doi: 10.1016/j.anbehav.2016.10.035

Tüzün, N., Debecker, S., Op de Beeck, L., and Stoks, R. (2015). Urbanisation shapes behavioural responses to a pesticide. Aquat. Toxicol. 163, 81-88. doi: 10.1016/j.aquatox.2015.04.002

Tüzün, N., Müller, S., Koch, K., and Stoks, R. (2017). Pesticide-induced changes in personality depend on the urbanization level. Anim. Behav. 134, 45-55. doi: 10.1016/j.anbehav.2017.10.007

Vindas, M. A., Gorissen, M., Höglund, E., Flik, G., Tronci, V., Damsgård, B., et al. (2017). How do individuals cope with stress? Behavioural, physiological and neuronal differences between proactive and reactive coping styles in fish. J. Exp. Biol. 220, 1524-1532. doi: 10.1242/jeb.153213

Vinebrooke, D. R., Cottingham, L. K., Marten Scheffer, N. J., Dodson, I. S., Maberly, C. S., and Sommer, U. (2004). Impacts of multiple stressors on biodiversity and ecosystem functioning: the role of species co-tolerance. Oikos 104, 451-457. doi: $10.1111 / j .0030-1299.2004 .13255 . x$

Ward, A. J. W., Duff, A. J., Horsfall, J. S., and Currie, S. (2008). Scents and scentsability: pollution disrupts chemical social recognition and shoaling in fish. Proc. R. Soc. B Biol. Sci. 275, 101-105. doi: 10.1098/rspb.2007.1283

Weber, D. N. (2006). Dose-dependent effects of developmental mercury exposure on C-start escape responses of larval zebrafish Danio rerio. J. Fish Biol. 69, 75-94. doi: $10.1111 /$ j.1095-8649.2006.01068.x

Weis, J. S., Smith, G., Zhou, T., Santiago-Bass, C., and Weis, P. (2001). Effects of Contaminants on Behavior: biochemical Mechanisms and Ecological Consequences Killifish from a contaminated site are slow to capture prey and escape predators; altered neurotransmitters and thyroid may be responsible for this behavior, which may produce population changes in the fish and their major prey, the grass shrimp. Bioscience 51, 209-217.

Weis, J. S., Smith, G. M., and Zhou, T. (1999). Altered predator/prey behavior in polluted environments: implications for fish conservation. Environ. Biol. Fishes 55, 43-51. doi: 10.1023/A:1007496528012

West-Eberhard, M. J. (2003). Developmental Plasticity and Evolution. Oxford: Oxford University Press. 
Whitehead, A., Clark, B. W., Reid, N. M., Hahn, M. E., and Nacci, D. (2017). When evolution is the solution to pollution: key principles, and lessons from rapid repeated adaptation of killifish (Fundulus heteroclitus) populations. Evol. Appl. 10, 762-783. doi: 10.1111/eva. 12470

Zala, S. M., and Penn, D. J. (2004). Abnormal behaviours induced by chemical pollution: a review of the evidence and new challenges. Anim. Behav. 68, 649-664. doi: 10.1016/j.anbehav.2004.01.005

Zhang, C., Jansen, M., Meester, L. D., and Stoks, R. (2018). Thermal evolution offsets the elevated toxicity of a contaminant under warming: a resurrection study in Daphnia magna. Evol. Appl. 11, 1425-1436. doi: 10.1111/eva.12637

Zhou, T., and Weis, J. S. (1998). Swimming behavior and predator avoidance in three populations of Fundulus heteroclitus larvae after embryonic and/or larval exposure to methylmercury. Aquat. Toxicol. 43, 131-148. doi: 10.1016/s0166$445 \times(98) 00052-6$

Conflict of Interest: The authors declare that the research was conducted in the absence of any commercial or financial relationships that could be construed as a potential conflict of interest.

Copyright (C) 2020 Jacquin, Petitjean, Côte, Laffaille and Jean. This is an open-access article distributed under the terms of the Creative Commons Attribution License (CC BY). The use, distribution or reproduction in other forums is permitted, provided the original author(s) and the copyright owner(s) are credited and that the original publication in this journal is cited, in accordance with accepted academic practice. No use, distribution or reproduction is permitted which does not comply with these terms. 